\title{
Gender difference in age of onset of Schizophrenia in South Rajasthan
}

\author{
Shakeel Ansari ${ }^{1}$, Shakila Mulla ${ }^{2}$ \\ ${ }^{1}$ Assistant Professor, Department of Psychiatry, \\ ${ }^{2}$ Associate Professor, Department of Community Medicine, \\ Jhalawar Medical College, Jhalawar, Rajasthan. \\ E-mail - mulla.shakila@yahoo.co.in \\ Corresponding Author - Shakila Mulla
}

\begin{abstract}
Background: Few Asian studies have contradicted established fact of earlier onset of schizophrenia among males. Current study was conducted to know gender based variation in age of onset of schizophrenia.

Methodology: Data pertaining to admitted cases of schizophrenia in a tertiary care centre was reviewed. Along with age of onset, detail socio-demographic and clinical details were gathered with the help of predesigned proforma. Correlates of age of onset were analyzed.

Results: Mean age of onset for females was $26.04 \pm 8.02$ years and for males $30.43 \pm 13.62$ years. Significant delay was observed in commencing treatment in whole sample. Unmarried status and positive family history were significant correlates of early age of onset.

Conclusion: Females have early age of onset of schizophrenia as also concluded by other Asian countries. This fact needs wide community based research and recognition among mental health practitioners.
\end{abstract}

Key words: schizophrenia, age of onset, gender difference, family history

(Paper received $-9^{\text {th }}$ July 2017, Peer review completed $-28^{\text {th }}$ July 2017 , Accepted $-6^{\text {th }}$ August 2017)

\section{INTRODUCTION}

Schizophrenia is a severe mental disorder affecting more than 21 million people worldwide [1]. According to WHO factsheet 2016, it is more common among males (12 million), than females (9 million). This factsheet also states that schizophrenia commonly starts earlier among men [1]. The incidence of schizophrenia peaks between 10 and 25 years for men and between 25 and 35 years for women [2]. In spite of these established global facts, few Asian studies have found either the reverse in the form of earlier age of onset among women or no difference in age of onset between the sexes [3-5].

The current study was performed to know the pattern of age of onset among schizophrenia cases from South Rajasthan and also to know whether it differs from established global facts. Other determinants were also assessed to know any impact on age of onset.

\section{METHODOLOGY}

The current study was conducted in a tertiary care centre situated at Jhalawar district of Rajasthan. It is a retrospective study. Three and half years data pertaining to admitted schizophrenia cases from January 2014 to June 2017 was reviewed from the medical record department of the hospital. Prior record could not be reviewed as it was unavailable. Sample size comprised complete enumeration keeping in view both inclusion and exclusion criteria. An inclusion criterion was all cases of schizophrenia admitted in the 
prescribed study duration. Patients having other psychotic disorders and co-morbid substance abuse were excluded from the study sample.

This centre serves both rural as well as urban population. Psychiatrists follow ICD-10 (The $10^{\text {th }}$ revision of the International Statistical Classification of Diseases and Related Health Problems) for the diagnosis of Schizophrenia. For data collection, a structured proforma was used to fill up socio-demographic and clinical details of schizophrenia cases. For study purpose, age of onset was considered as age at first psychotic symptoms. Additionally, delay in commencement of treatment was analyzed. Ethical approval was obtained from the Institutional Ethics Committee.

\section{STATISTICAL ANALYSIS}

For statistical analysis of qualitative data, chi square test was applied to know gender wise differences. For quantitative data, mean, standard deviation and standard error were calculated and the ' $\mathrm{t}$ ' test was applied for statistical analysis. A $p$ value of $<0.05$ is deemed significant, $<0.01$ as highly significant and $<0.0001$ as very highly significant. Data was entered in Microsoft excel sheet and analyzed using the Statistical Package for Social Sciences, version 20 (SPSS V20.0).

\section{RESULTS}

As per the inclusion criteria, a total of 180 cases of schizophrenia were included in the study. Out of 180 , 100 were females and 80 were males. Mean age of onset among females was $26.04 \pm 8.02$ years and for males $30.43 \pm 13.62$ years. This difference between two means has been found statistically highly significant (Table 1).

Table 1 - Gender difference in age of onset

\begin{tabular}{|c|c|c|c|c|}
\hline \multirow{2}{*}{ Gender } & \multirow{2}{*}{ Number } & \multicolumn{2}{|c|}{ Age of Onset } & Statistical Analysis \\
\cline { 3 - 4 } & & Mean & Standard deviation & $\mathrm{t}=2.689$ \\
& & 26.04 & 8.02 & $(\mathrm{df}=178)$ \\
Female & 100 & 30.43 & 13.63 & $\mathrm{p}=0.008^{*}$ \\
\hline Male & 80 & &
\end{tabular}

( $\mathrm{t}$ test used in the statistics, ${ }^{*} \mathrm{p}<0.05=$ significant $)$

Mean age of starting treatment for females was observed as $26.36 \pm 8.28$ years and for males was $30.61 \pm$ 13.65 years. To know about delay in starting treatment for the whole sample size, difference between mean age of onset (27.99 years) and mean age of starting treatment ( 28.25 years) was analysed by the ' $t$ ' test. It was statistically very highly significant $(\mathrm{p}<0.0001)$.

History of non-compliance was compared gender wise. 8 case sheets ( 5 females, 3 males) had not mentioned about non-compliance so they were not included in analysis. Non-compliance was found more in males and it was statistically significant (Table 2).

Table 2 - Gender difference in Non-compliance

\begin{tabular}{|c|c|c|c|c|}
\hline \multirow{2}{*}{ Gender } & \multicolumn{2}{|c|}{ Non-compliance } & \multirow{2}{*}{ Total } & \multirow{2}{*}{ Statistical Analysis } \\
\cline { 2 - 3 } & No (\%) & Yes (\%) & & \\
\hline Female & $12(12.63)$ & $83(87.37)$ & 95 & \multirow{2}{*}{$\chi^{2}=4.464}$, \\
\cline { 1 - 3 } Male & $2(2.60)$ & $75(97.40)$ & 77 & $1)$ \\
\hline Total & $14(8.14)$ & $158(91.86)$ & 172 & $\mathrm{p}=0.035^{\star}$ \\
\hline
\end{tabular}

(Chi square test used in the assessment, ${ }^{*} \mathrm{p}<0.05$ significant)

Association of age of onset with various socio-demographic factors was analyzed as shown in Table 3. 
Table 3: Association of Age of onset of schizophrenia with socio-demographic variables

\begin{tabular}{|c|c|c|c|c|c|c|c|}
\hline \multicolumn{2}{|l|}{ Variables } & \multirow{2}{*}{$\begin{array}{l}\text { Number } \\
163\end{array}$} & \multicolumn{3}{|c|}{ Age of Onset } & 't' value & 'p' value \\
\hline \multirow{2}{*}{ Religion } & Hindu & & $\begin{array}{l}\text { Mean } \\
28.09\end{array}$ & $\begin{array}{l}\begin{array}{l}\text { Standard } \\
\text { deviation }\end{array} \\
11.26\end{array}$ & \begin{tabular}{|l}
$\begin{array}{l}\text { Standard } \\
\text { error mean }\end{array}$ \\
0.88
\end{tabular} & \multirow{2}{*}{0.375} & \multirow{2}{*}{0.708} \\
\hline & Muslim & 17 & 27.03 & 9.11 & 2.21 & & \\
\hline \multirow[t]{2}{*}{ Residence } & Rural & 155 & 28.29 & 11.38 & 0.914 & \multirow[t]{2}{*}{0.910} & \multirow[t]{2}{*}{0.364} \\
\hline & Urban & 25 & 26.12 & 8.82 & 1.76 & & \\
\hline \multirow{2}{*}{$\begin{array}{l}\text { BPL } \\
\text { card holder }\end{array}$} & Yes & 10 & 26.20 & 6.87 & 2.17 & \multirow[t]{2}{*}{-0.525} & \multirow[t]{2}{*}{0.600} \\
\hline & No & 170 & 28.09 & 11.26 & 0.86 & & \\
\hline \multirow[t]{2}{*}{ Marital status } & Married & 151 & 29.84 & 11.06 & 0.90 & \multirow[t]{2}{*}{5.546} & \multirow[t]{2}{*}{$<0.0001^{*}$} \\
\hline & Unmarried & 29 & 18.33 & 3.47 & 0.64 & & \\
\hline \multirow{2}{*}{$\begin{array}{l}\text { Family history of } \\
\text { schizophrenia }\end{array}$} & Yes & 17 & 22.53 & 6.65 & 1.61 & \multirow[t]{2}{*}{-2.160} & \multirow[t]{2}{*}{$0.032^{*}$} \\
\hline & No & 163 & 28.56 & 11.29 & 0.88 & & \\
\hline
\end{tabular}

(BPL - Below Poverty Line) ( $\mathrm{t}$ test used in the assessment, $\left.{ }^{*} \mathrm{p}<0.005\right)$

Age of onset was found significantly early in unmarried persons and those having positive family history for schizophrenia.

\section{DISCUSSION}

This study indicated significant early age of onset in females as compared to males. It reconfirms regional variation in the age of onset of schizophrenia studied by previous Indian study [3] and it clearly differs from the global facts.

Significant delay was found in seeking psychiatric help among cases of schizophrenia and patient's case sheets affirmed that visits to faith healers were responsible for this delay. Another study has also concluded that Asians were more likely to have had longer duration of symptoms prior to seeking help for schizophrenia [6]. Non-compliance was observed more with male patients, which is in accordance with other studies [7-8]. In our study more non-compliance among males could be because many male patients had responded that to resume their work they had stopped taking medicines. However, this needs more investigation.

Religion, rural or urban residence and socio-economic status were found to have no bearing on age of onset in schizophrenia. Unmarried persons had shown significantly very early age of onset but this fact cannot be generalized. All unmarried persons from our study sample belonged to age range of 16-28 years and the same replicated in their early age of onset. Important determinant of age of onset found in our study was positive family history of schizophrenia. Presence of family history makes a person more prone to early onset of schizophrenia. This fact has been confirmed by a meta-analysis [9]. Further another study has emphasized that family history of schizophrenia appears to be the most significant factor that eliminates the gender differences in age at onset of schizophrenia [4].

\section{CONCLUSION}

Age of onset is earlier in females as compared to males. It is contradictory to the established global facts. This needs to be investigated further and confirmed on large scale sample. Also mental health awareness is the need of time to reduce delay in starting treatment due to frequent visits to faith-healers.

\section{REFERENCES}

1. WHO Factsheet on Schizophrenia. Reviewed April 2016. Available from http://www.who.int/mediacentre/factsheets/fs397/en/ 
2. Buchanan RW, Carpenter WT. Concept of schizophrenia. In Kaplan \& Sadock's Comprehensive Textbook of Psychiatry (8th edition) (Editors BJ Sadock \& VA Sadock). Lippincott Williams \& Wilkins, 2005

3. Venkatesh BK, Thirthalli J, Naveen MN, Kishorekumar KV, Arunachala U, Venkatasubramanian G. Sex difference in age of onset of schizophrenia: findings from a community-based study in India. World Psychiatry 2008;7(3):173-6.

4. Naqvi H, Khan MM, Faizi A. Gender differences in age at onset of schizophrenia. J Coll Phys Surg Pak 2005;15(6):345-8.

5. Naqvi I, Murtaza M, Nazir MR, Naqvi HA. Gender difference in age at onset of Schizophrenia: a cross sectional study from Pakistan. J Pak Med Assoc 2010;60(10):886-9.

6. Bhugra D, Corridan B, Rudge S, Leff J, Mallett R. Social Factors and First Onset Schizophrenia Among Asians and Whites. Int J Soc Psychiatry 1999;45(3):162-70.

7. Rao KN, George J, Sudarshan CY, Begum S. Treatment compliance and noncompliance in psychoses. Indian J Psychiatry 2017;59:69-76.

8. Sellwood W, Tarrier N. Demographic factors associated with extreme non-compliance in schizophrenia. Soc Psych Psychiatr Epidemiol 1994;29(4):172-7.

9. Esterberg ML, Trotman MD, Holtzman C, Compton MT, Walker EF. The impact of a family history of psychosis on age-at-onset and positive and negative symptoms of schizophrenia: A meta-analysis. Schizophr Res 2010;120:121-30.

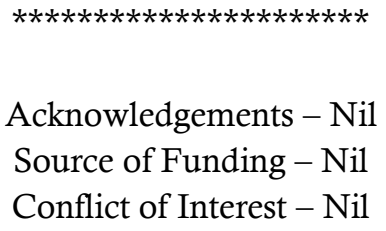

